Tohoku J. exp. Med., 1977, 121, 327-335

\title{
The Effect of Atropine on Ventriculoatrial Conduction during Ventricular Pacing in Patients with and without Wolff-Parkinson- White Syndrome
}

\author{
Meitchi Ito, Susumu Shinoda, Mrchio Nagashima, Tatsuji \\ Furuta, Toshiniro Tokudome, Masamichi Otaki and \\ HIKOYUKI SUZUkI \\ Department of Internal Medicine, Sendai City Hospital, Sendai
}

\begin{abstract}
Ito, M., Shinoda, S., Nagashmia, M., Furuta, T., Tokudome, T., Otaki, M. and SuzukI, H. The Effect of Atropine on Ventriculoatrial Conduction during Ventricular Pacing in Patients with and without Wolff-Parkinson-White Syndrome. Tohoku J. exp. Med., 1977, 121, (4), 327-335 - Electrophysiological studies were performed in five patients, two with and three without Wolff-ParkinsonWhite (WPW) syndrome. In the former patients group, the paroxysmal supraventricular tachycardia (PSVT) was concluded to reflect the circus movement utilizing the normal atrioventricular $(A-V)$ conduction system for antegrade conduction and the Kent bundle for the retrograde conduction. Ventriculoatrial conduction time (VACT) was measured during ventricular pacing before and after the administration of atropine sulfate. In patients without WPW syndrome, the VACT prolonged and subsequently second degree ventriculoatrial block developed when the pacing rate was increased progressively and atropine facilitated the retrograde conduction, suggesting the ventriculoatrial conduction took place via the normal $A-V$ pathway. In contrast, the VACT in patients with WPW syndrome remained unchanged during ventricular pacing at rates of $145 / \mathrm{min}$ and more both before and after atropine, indicating the retrograde conduction was taking place through the Kent bundle. It is discussed that the analysis of the VACT before and after atropine serves as an aid to differentiate the underlying mechanisms of PSVT in patients with WPW syndrome.- atropine; ventricular pacing; Wolff-Parkinson-White syndrome; paroxysmal supraventricular tachycardia; retrograde conduction
\end{abstract}

It is a well-known fact that atropine in the dosage commonly used facilitates the atrioventricular $(\mathrm{A}-\mathrm{V})$ conduction of impulses through the normal A-V conduction system (Damato et al. 1969; Akhtar et al. 1974; Ito 1976). In contrast, this drug exerts no effect on the $\mathrm{A}-\mathrm{V}$ conduction through the Kent bundle in patients with Wolff-Parkinson-White (WPW) syndrome (Ito 1976). However, little work has been done concerning the effect of atropine on the retrograde ventriculoatrial conduction in cases of WPW syndrome or other cases. To investigate the mode of ventriculoatrial conduction and the effect of atropine on this retrograde conduction, electrophysiological observations have been made utilizing intracardiac recording techniques and ventricular pacing. It is the purpose of this paper to describe that

Received for publication, October $23,1976$. 
the ventricular pacing both before and after atropine administration is of value to the differentiation of underlying mechanisms of paroxysmal supraventricular tachycardia (PSVT) in patients with WPW syndrome.

\section{Materials and Methods}

The subjects consisted of five patients, four males and one fermale with an age range from 38 to 58 years (Table 1). Two patients had WPW syndrome, one type A and the other type B. They had experienced recurrent episodes of PSVT. None of the remaining three patients exhibited evidence of ventricular preexcitation on surface electrocardiogram. Electrophysiological studies were performed in the nonsedated and the postabsorptive states. Three or four electrode catheters with $10 \mathrm{~mm}$ interelectrode distances were introduced percutaneously under local anesthesia into femoral and antecubital veins.

A bipolar catheter was positioned at the right ventricular apex for pacing. A quadripolar catheter was placed in the high right atrium for recording high right atrial electrogram (HRA) and for atrial stimulation. A bi- or hexapolar catheter was positioned across the tricuspid valve for recording $\mathrm{His}$ bundle electrogram (HBE) according to Scherlag et al. (1969). In Cases 4 and 5, low lateral right atrial electrogram (LLRA) was also recorded from proximal pair of the hexapolar catheter. In Case 5, an additional bipolar catheter was placed in the distal coronary sinus for recording left atrial electrogram (LA). These intracardiac recordings were made simultaneously with two to four leads of surface electrocardiogram on a photographic recorder at a paper speed of $100 \mathrm{~mm} / \mathrm{sec}$ as described previously (Ito 1976).

The right ventricle was paced at progressively increasing rates, as presented in Table 1. Following the control study, $1 \mathrm{mg}$ of atropine sulfate was given intravenously for $1 \mathrm{~min}$. At least $3 \mathrm{~min}$ after the administration of atropine, ventricular pacing was repeated. PIHRA interval, from the ventricular pacing impulse to the onset of rapid deflection of HRA, was defined as the ventriculoatrial conduction time (VACT). Furthermore, right atrium was stimulated with an increase in rate or prematurity.

TABLE 1. Ventriculoatrial conduction time (PI-HRA interval) during ventricular pacing

\begin{tabular}{|c|c|c|c|c|c|c|c|c|c|c|c|c|}
\hline \multirow{2}{*}{$\begin{array}{l}\text { Case } \\
\text { No. }\end{array}$} & \multirow{2}{*}{$\begin{array}{l}\text { Age } \\
\text { Sex }\end{array}$} & \multirow{2}{*}{$\begin{array}{l}\text { ECG } \\
\text { findings }\end{array}$} & \multicolumn{10}{|c|}{ Ventricular pacing rate $(/ \mathrm{min})$} \\
\hline & & & & 75 & 84 & 92 & 103 & 113 & 124 & 135 & 145 & 182 \\
\hline \multirow[t]{2}{*}{1} & $58 \mathrm{M}$ & $\mathrm{SAB}, \mathrm{CRBBB}$ & $\mathrm{c}$ & - & 35 & 37 & & $2: 1$ & 2: & 2.1 & $2: 1$ & - \\
\hline & & & $\mathrm{a}$ & 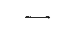 & 31 & 3. & 320 & & 0 & $W$ & $2: 1$ & - \\
\hline \multirow[t]{2}{*}{2} & $49 \mathrm{M}$ & $\mathrm{SB}, \mathrm{PVB}$ & $c$ & 185 & 19 & $2: 1$ & $2: 1$ & $2: 1$ & $2: 1$ & $2: 1$ & $2: 1$ & - \\
\hline & & & a & - & 140 & 145 & 145 & 150 & 160 & W & $W$ & - \\
\hline \multirow[t]{2}{*}{3} & $48 \mathrm{M}$ & $\mathrm{SB}$ & c & $2: 1$ & $2: 1$ & $2: 1$ & $2: 1$ & $2: 1$ & $2: 1$ & - & - & - \\
\hline & & & $a$ & - & 220 & 225 & 230 & $W$ & $2: 1$ & - & - & - \\
\hline \multirow[t]{2}{*}{4} & $44 \mathrm{~F}$ & WPW, Type B & $\mathrm{c}$ & - & - & - & 180 & 180 & 180 & 180 & 180 & 180 \\
\hline & & & a & - & - & - & - & 一 & - & - & 180 & 180 \\
\hline \multirow[t]{2}{*}{5} & $38 \mathrm{M}$ & WPW, Type A & $\mathrm{c}$ & - & 一 & 210 & 210 & 210 & 210 & 210 & 210 & 210 \\
\hline & & & $\mathrm{a}$ & - & - & - & - & - & 130 & 140 & 210 & 210 \\
\hline
\end{tabular}

PI-HPA interval was measured in msec from ventricular pacing impulse to onset of rapid deflection of high right atrial electrogram.

Abbreviations: $\mathrm{M}=$ male, $\mathrm{F}=$ female, $\mathrm{SAB}=$ sinoatrial block, $\mathrm{CRBBB}=$ complete right bundle branch block, $\mathrm{SB}=$ sinus bradycardia, $\mathrm{PVB}=$ premature ventricular beat, $\mathrm{WPW}=$ Wolff-Parkinson-White syndrome, $c=$ control, $a=$ after atropine, $W=$ Wenckebach type ventriculoatrial block, $2: 1=2: 1$ ventriculoatrial block 


\section{Results}

VACT in the present five patients is summarized in Table 1. In Cases 1 and 2, the VACT showed the prolongation and subsequent second degree ventriculoatrial block when the rate of ventricular pacing was progressively increased. In Case 3 with $2: 1$ ventriculoatrial block during ventricular pacing before atropine, the VACT in ventriculoatrial conducted beat lengthened progressively with an increase in the pacing rate. Following the administration of atropine, the VACT shortened and the ventricular pacing rate at which second degree ventriculoatrial
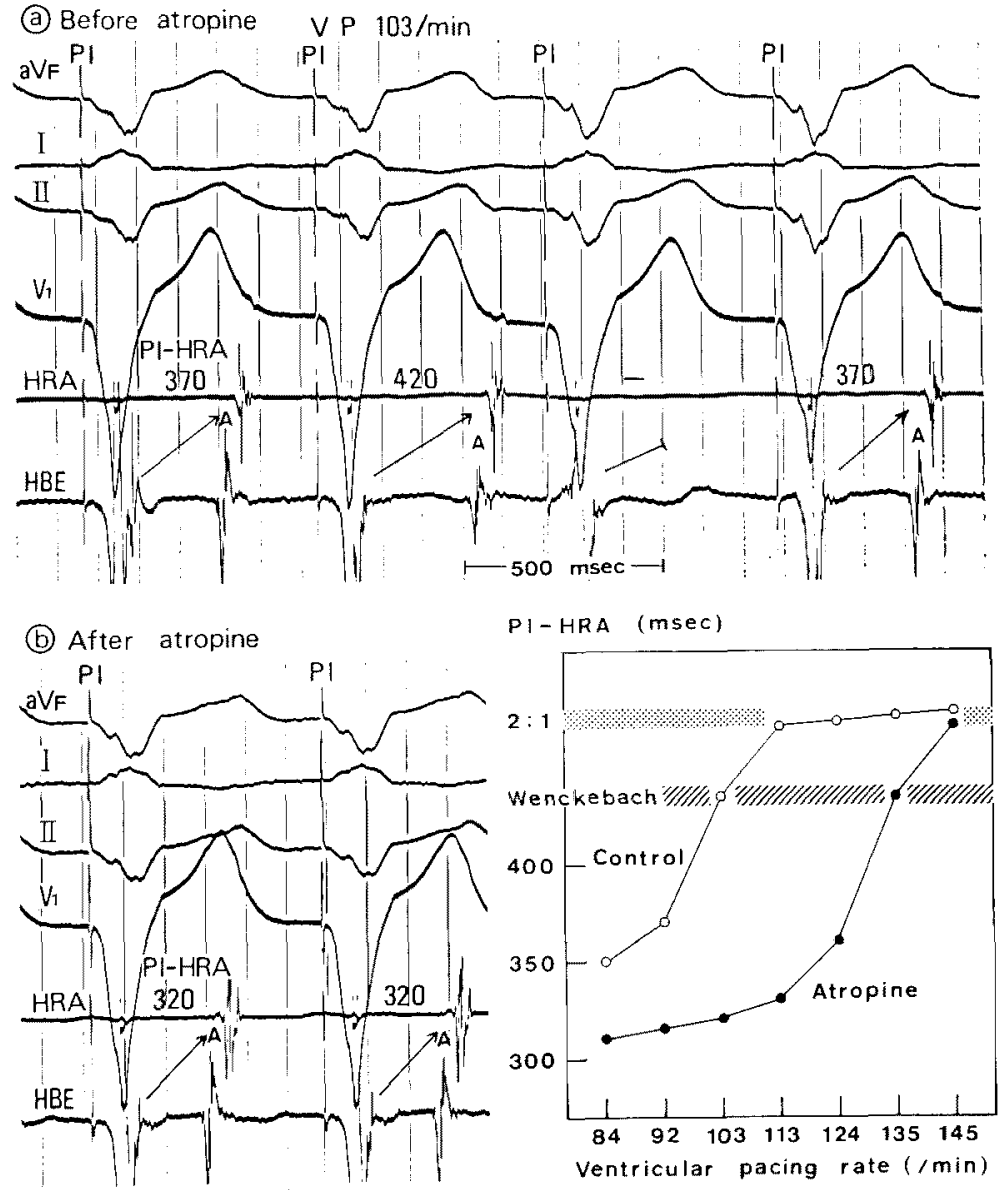

Fig. 1. Case 1. Simultaneous recording of surface electrocardiograms (leads aVF, I, II, $V_{1}$ ) and intracardiac electrograms during ventricular pacing (VP) at rate of $103 / \mathrm{min}$. In this and subsequent figures: HRA=high right atrial electrogram; $\mathrm{HBE}=\mathrm{His}$ bundle electrogram; $A=$ low septal right atrial potential; $P I=$ pacing impulse. PIHRA interval is shown in msec. Wenckebach type second degree ventriculoatrial block is observed before atropine (a), and 1:1 retrograde conduction after atropine (b). HRA is preceded by A on HBE. Relation between PI-HRA interval and pacing rate before (open circles) and after (solid circles) atropine is graphically represented in the bottom right. Atropine facilitates retrograde conduction. 


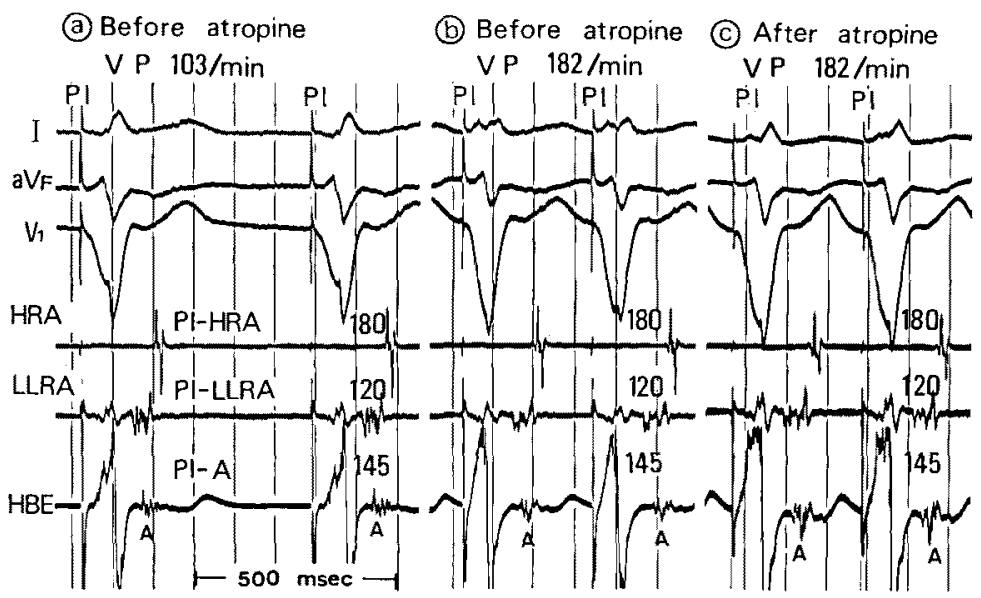

(d) PSVT

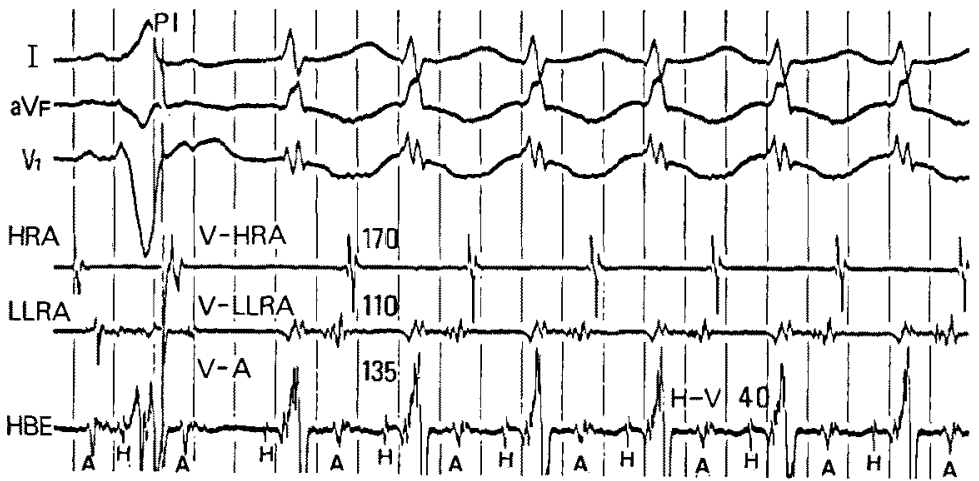

Fig. 2. Case 4. Ventricular pacing at rates of $103 / \mathrm{min}$ (a) and $182 / \mathrm{min}$ (b) before atropine, and at rate of $182 / \mathrm{min}$ after atropine (c). PI-HRA, PI-LLRA and PI-A intervals remain constant. Paroxysmal supraventricular tachycardia (PSVT) initiated by premature atrial stimulation (d). H represents the His bundle potential. LLRA (low lateral right atrial electrogram) is followed by A on HBE and HRA. Note that retrograde atrial activation sequence during PSVT is identical to those of ventricular pacing.

block developed increased in Cases 1 (Fig, 1), 2 and 3 . In these patients, the atrial deflection on $\mathrm{HBE}$, low septal right atrial electrogram, preceded HRA with constant interval.

In Cases 4 and 5 , the existence of the Kent bundle was suggested, since a progressive increase in rate or prematurity of atrial pacing provoked a progressive increase in duration and aberration of QRS complex (Narula 1973). During the PSVT initiated by means of premature atrial stimulation, the QRS complex revealed the loss of delta wave, and was preceded by His bundle deflection with normal H-V interval (Figs. 2d and 3c). Both cases exhibited 1:1 ventriculoatrial conduction during the ventricular pacing even at rate of $182 / \mathrm{min}$.

In Case 4, the VACT remained unchanged throughout with fixed atrial activation sequence, depsite not only the ventricular pacing at increasing rates (Fig. 2a, 
Before atropine

(a) $\vee P 92 / \mathrm{min}$

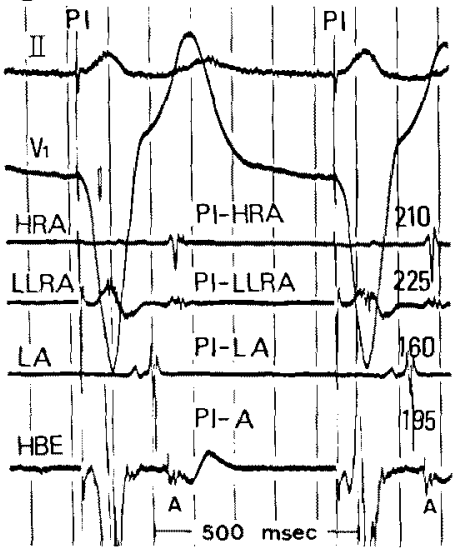

(b) VP $182 / \mathrm{min}$

(C) PSVT

After atropine

(d) VP $124 / \mathrm{min}$
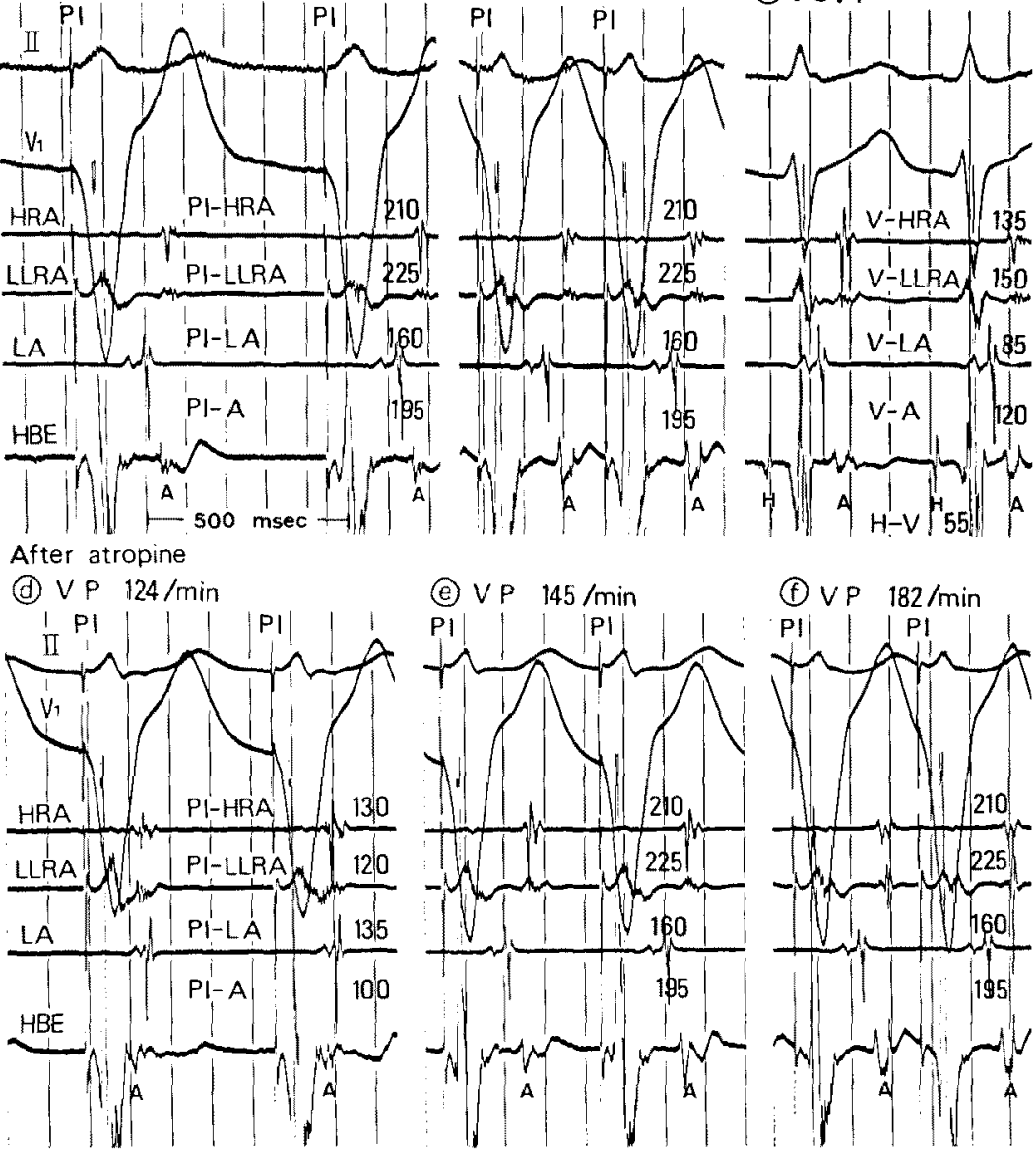

(e) $V P \quad 145 / \mathrm{min}$
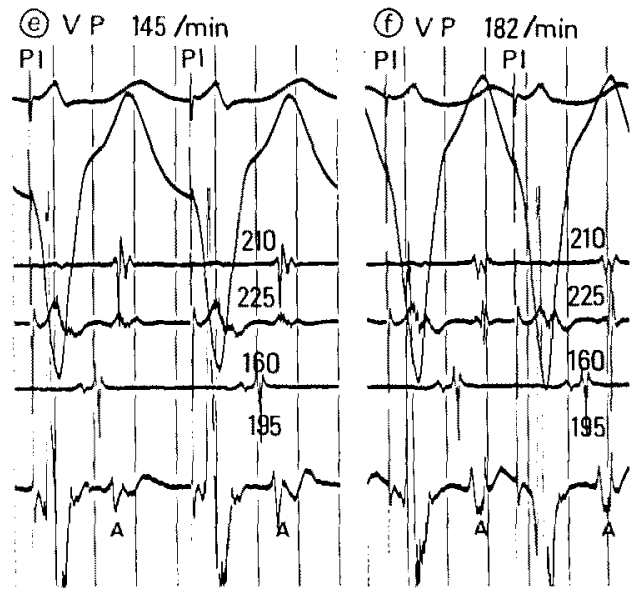

Fig. 3. Case 5. During ventricular pacing at rates of $92 / \mathrm{min}$ (a) and $182 / \mathrm{min}$ (b) before atropine, and at rates of $145 / \mathrm{min}$ (e) and $182 / \mathrm{min}$ (f) after atropine, the earliest. retrograde atrial activation occurs in LA (left atrial electrogram) recorded from distal coronary sinus. The sequence of atrial activation is identical to that of PSVT (c). During ventricular pacing at rate of $124 / \mathrm{min}$ after atropine (d), the initjal retrograde atrial activation occurs in $A$ on $\mathrm{HBE}$.

b) but also the atropine administration (Fig. 2c). The retrograde atrial activation sequence was identical to that of PSVT (Fig. 2d). During the PSVT, the atrial deflection on HBE was preceded by LLRA, indicating circus movement showing the ventriculoatrial conduction through right-sided Kent bundle (Gallagher et al. 1975; Svenson et al. 1975).

In Case 5, the VACT remained constant during ventricular pacing before atropine and at rates between 145 and $182 / \mathrm{min}$ after atropine (Fig. 3a, b, e, f), but shortened during pacing at rates of 124 to $135 / \mathrm{min}$ after atropine (Fig. $3 \mathrm{~d}$ ). The mode of retrograde atrial activation obtained during ventricular pacing is graphically presented in Fig. 4. PI-A interval (from the ventricular pacing impulse to 


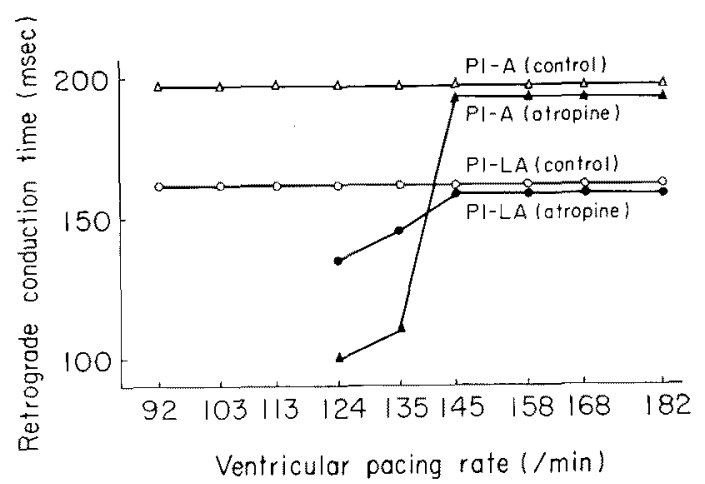

Fig. 4. Retrograde conduction time during ventricular pacing in Case 5. PI-A and PI-LA intervals on the ordinate are plotted against ventricular pacing rate on the abscissa. In the control study (open marks), both intervals remains unchanged. Following the atropine administration (solid marks), the curves reveal gradual prolongation during ventricular pacing at rates of 124 to $135 / \mathrm{min}$. At rate of $145 / \mathrm{min}$ both intervals suddenly lengthen accompanied by change of atrial activation sequence, and show plateau at rates above that.

the onset of atrial deflection on HBE) and PI-LA interval (from the ventricular pacing impulse to the onset of LA) were plotted for simplicity from two of four electrograms. The PSVT (Fig. 3c) revealed the same retrograde atrial activation sequence as those of ventricular pacing in the control study and higher rates after atropine (Fig. 3a, b, e, f).

During the PSVT, the earliest retrograde atrial activation occurred in the LA recorded from the distal coronary sinus, implying the participation of the leftsided Kent bundle in the retrograde route of the PSVT circuit (Wellens and Durrer 1975; Gallagher et al. 1975; Svenson et al. 1975).

\section{DISCUSSION}

Ventriculoatrial conduction during ventricular pacing

In patients without ventricular preexcitation, the A-V conduction time prolongs with an increase in rate or prematurity of atrial pacing and shortens after administration of atropine (Damato et al. 1969; Akhtar et al. 1974; Ito 1976). In addition, atropine increases the atrial pacing rate at which Wenckebach type $\mathrm{A}-\mathrm{V}$ block develops (Damato et al. 1969). The studies utilizing HBE have elucidated that atropine facilitates $A-V$ nodal transmission and exerts no effect on intraatrial conduction or propagation through the His-Purkinje system (Damato et al. 1969; Akhtar et al. 1974; Ito 1976). In Cases 1 (Fig. 1), 2 and 3, both the change of VACT during ventricular pacing and the effect of atropine were similar to the response of $A-V$ node during atrial pacing, suggesting the retrograde conduction via the normal A-V conduction system.

In Cases 4 (Fig. 2) and 5 (Figs. 3 and 4), on the other hand, the VACT revealed 
a different mode from that of cases without WPW syndrome. Narula (1974) suggested the presence of bypass pathway of A-V node, functional in retrograde direction only, in patients without evidence of WPW syndrome but with constant VACT throughout despite an increase in ventricular pacing rate. The antegrade $A-V$ conduction time over Kent bundle remains unchanged, irrespective of the atropine administration (Ito 1976) as well as the atrial pacing with high rates or prematurity (Narula 1973). It has been also described that no significant change in the VACT is seen following the ventricular stimulation with an increasing prematurity in patients with WPW syndrome (Wellens and Durrer 1974).

Therefore, it is more likely that the retrograde conduction is mediated by way of the Kent bundle rather than the normal $A-V$ pathway, when the VACT remains constant during ventricular pacing both before and after atropine. This conduction mode is supported by the earliest retrograde atrial activation of LLRA and LA in Cases 4 and 5, respectively. Because the low septal right atrium in the vicinity of $A-V$ node is activated earlier than the other sites of both atria during the retrograde conduction through the normal $\mathrm{A}-\mathrm{V}$ pathway, the earliest retrograde atrial activation may occur in atrial deflection on HBE (Svenson et al. 1974; Amat-yLeon et al. 1976).

During the ventricular pacing in Case 5, two kinds of the earliest atrial activation were observed as follows: atrial deflection on HBE at lower rates after atropine (Fig. 3d), and LA before atropine and higher rates after the drug administration (Fig. 3a, b, e, f). The VACT showing the former sequence was shorter than that of the latter. This finding implies that the retrograde impulse through the normal $A-V$ pathway is facilitated by atropine and consequently arrived at the low septal right atrium earlier than through the Kent bundle. A sudden increment of PI-A interval with an increase in pacing rate (Fig. 4) could result from failure of retrograde conduction through the normal $A-V$ pathway (Svenson et al. 1975). Thus, the former and latter retrograde atrial activiations are considered to be predominantly mediated via the normal $\mathrm{A}-\mathrm{V}$ pathway and the Kent bundle, respectively.

\section{Ventriculoatrial conduction during PSVT in WPW syndrome}

In patients with WPW syndrome, the PSVT has been generally thought to be due to a circus movement. This mechanism is supported by the electrophysiological studies using intracardiac recordings and cardiac stimulation (Castillo and Castellanos 1970; Narula 1973; Svenson et al. 1974, 1975; Wellens and Durrer 1974, 1975; Wellens 1975; Gallagher et al. 1975), and also by the surgical treatment characterized by disappearance of PSVT after the ablation of Kent bundle (Cobb et al. 1968; Svenson et al. 1974; Gallagher et al. 1975).

Various reentry localizations involved in the PSVT have been proposed. In the majority of patients with WPW syndrome, the PSVT is regarded as the result of the circus movement of impulses passing through the normal A-V pathway to ventricles and the retrograde conduction through the Kent bundle to atria (Narula 
1973; Wellens and Durrer 1974, 1975; Gallagher et al. 1975). The circuit is rarely composed of the Kent bundle for the antegrade conduction and the normal A-V pathway for the retrograde conduction (Wellens and Durrer 1974). Furthermore, the PSVT may be sustained by the reentry within A-V node (Neuss and Schlepper 1974; Wellens 1975; Wellens and Durrer 1975), sinoatrial node (Wu et al. 1975; Wellens 1975) or His-Purkinje system (Neuss and Schlepper 1974).

The simultaneous recording of activities from multiple sites of both atria is of use as shown in Cases 4 (Fig. 2d) and 5 (Fig. 3c). The location of the earliest atrial electrogram is considered the site nearest the Kent bundle (Svenson et al. 1975). When the earliest retrograde atrial activation occurs in LLRA and LA during the PSVT, the right- and left-sided Kent bundles are concluded to be responsible for the retrograde route of the PSVT circuit, respectively (Gallagher et al. 1975; Wellens and Durrer 1975; Svenson et al. 1975). However, this method would have no value, if the catheter was unsuccessfully inserted into the coronary sinus or the left atrial cavity through atrial septal defect or patent foramen ovale in patients with retrogradely conducting left-sided Kent bundle.

Without recording atrial activity, LA or LLRA, close to the atrial end of Kent bundle, the electrophysiological findings in patients with PSVT showing the retrograde conduction over Kent bundle would be similar to those of $A-V$ nodal reentrant PSVT (Castillo and Castellanos 1970; Sung et al. 1976). Accordingly, it is most difficult to differentiate between these two mechanisms of PSVT, especially when the earliest retrograde atrial activation occurs near the atrial septum (Svenson et al. 1974, 1975). This differentiation has become more important from a therapeutic as well as theoretical point of view, since the surgical treatment for the Kent bundle is not effective for patients with the latter circuit but curable for the former type. Therefore, efforts have to be made to obtain as much information on PSVT as possible.

In the present two patients with WPW syndrome, the VACT remained unchanged during the ventricular pacing at high rates both before and after atropine. The sequence of retrograde atrial activation during the PSVT was identical to that of the ventricular pacing. When these findings are observed, therefore, it is strongly suggested that the Kent bundle functioned as the retrograde pathway of the PSVT circuit. Thus, the combination of the ventricular pacing with the atropine administration serves as an aid to differentiate the underlying mechanisms of PSVT in patients with WPW syndrome.

\section{Acknowledgment}

Grateful acknowledgment is made to Dr. Mitsuo Tanno for his guidance, and Mr. Kazuya Kuriyagawa and Mr. Kenji Takahashi for their technical assistance.

\section{References}

1) Akhtar, M., Damato, A.N., Caracta, A.R., Batsford, W.P., Josephson, M.E. \& Lau, S.H. (1974) Electrophysiologic effects of atropine on atrioventricular conduction studied by His bundle electrogram. Amer. J. Cardiol., 33, 333-343. 
2) Amat-y-Leon, F., Dhingra, R.C., Wu, D., Denes, P., Wyndham, C. \& Rosen, K.M. (1976) Catheter mapping of retrograde atrial activation. Observations during ventricular pacing and $\mathrm{AV}$ nodal re-entrant paroxysmal tachycardia. Brit. Heart $J$, 38, 355-362.

3) Castillo, C.A. \& Castellanos, A., Jr. (1970) His bundle recordings in patients with reciprocating tachycardias and Wolff-Parkinson-White syndrome. Circulation, 42, 271-285.

4) Cobb, F.R., Blumenschein, S.D., Sealy, W.C., Boineau, J.P., Wagner, G.S. \& Wallace, A.G. (1968) Successful surgical interruption of the bundle of Kent in a patient with Wolff-Parkinson-White syndrome. Circulation, 38, 1018-1029.

5) Damato, A.N., Lau, S.H., Helfant, R.H., Stein, E., Berkowitz, W.D. \& Cohen, S.I. (1969) Study of atrioventricular conduction in man using electrode catheter recordings of $\mathrm{His}$ bundle activity. Circulation, 39, 287-296.

6) Gallagher, J.J., Gilbert, M., Svenson, R.H., Sealy, W.C., Kasell, J. \& Wallace, A.G. (1975) Wolff-Parkinson-White syndrome. The problem, evaluation, and surgical correction. Circulation, 51, 767-785.

7) Ito, M. (1976) The effects of atropine on atrio-ventricular conduction in patients with Wolff-Parkinson-White syndrome. Studies with His bundle electrogram. Jap. Circul. J., 40, 1285-1300.

8) Narula, O.S. (1973) Wolff-Parkinson-White syndrome. A review. Circulation, 47, 872 -887 .

9) Narula, O.S. (1974) Retrograde pre-excitation. Comparison of antegrade and retrograde conduction intervals in man. Circulation, 50, $1129-1143$.

10) Neuss, H. \& Schlepper, M. (1974) Unusual re-entry mechanisms in patients with Wolff-Parkinson-White syndrome. Brit. Heart J., 36, 880-887.

11) Scherlag, B.J., Lau, S.H., Helfant, R.H., Berkowitz, W.D., Stein, E. \& Damato, A.N. (1969) Catheter technique for recording $\mathrm{His}$ bundle activity in man. Circulation, 39, $13-18$.

12) Sung, R.J., Castellanos, A., Gelband, H. \& Myerburg, R.J. (1976) Mechanism of reciprocating tachycardia initiated during sinus rhythm in concealed WolffParkinson-White syndrome. Report of a case. Circulation, 54, 338-344.

13) Svenson, R.H., Gallagher, J.J., Sealy, W.C. \& Wallace, A.G. (1974) An electrophysiologic approach to the surigcal treatment of the Wolff-Parkinson-White syndrome. Report of two cases utilizing catheter recording and epicardial mapping techniques. Circulation, 49, 799-804.

14) Svenson, R.H., Miller, H.C., Gallagher, J.J. \& Wallace, A.G. (1975) Electrophysiological evaluation of the Wolff-Parkinson-White syndrome. Problems in assessing antegrade and retrograde conduction over the accessory pathway. Circulation, 52, $552-562$.

15) Wellens, H.J.J. (1975) Contribution of cardiac pacing to our understanding of the Wolff-Parkinson-White syndrome. Brit. Heart J., 37, 231-24I.

16) Wellens, H.J. \& Durrer, D. (1974) Patterns of ventriculo-atrial conduction in the Wolff-Parkinson-White syndrome. Circulation, 49, 22-31.

17) Wellens, H.J.J. \& Durrer, D. (1975) The role of an accessory atrioventricular pathway in reciprocal tachycardia. Observations in patients with and without the WolffParkinson-White syndrome. Circulation, 52, 58 72.

18) Wu, D., Amat-y-Leon, F., Denes, P., Dhingra, R.C., Pietras, R.J. \& Rosen, K.M. (1975) Demonstration of sustained sinus and atrial re-entry as a mechanism of paroxysmal supraventricular tachycardia. Circulation, 51, 234-243. 